\title{
Are You HIP?: How One Latinx Learning Community Integrates Ten High-Impact Practices to Foster Student Success. A Practice Report
}

\author{
Sandra M. Gonzales \\ Wayne State University, United States \\ Stefanie T. Baier \\ Michigan State University, United States \\ Ethriam C. Brammer \\ University of Michigan, United States
}

\begin{abstract}
This report shares practices from a successful Latinx Studies learning community model at an urban research-intensive university in the Midwestern United States. The learning community model offers a tiered developmental curriculum to support the three different stages of a student's journey, from enrollment to graduation. The three distinct phases of the learning community model are: a pre-college summer enrichment program, a first- and second-year college scholars program and a third and fourth-year college-to-career component. The model also integrates 10 out of 11 of Kuh's (2008) high impact practices demonstrated to support student engagement and success for students making a direct transition from high school to university. The authors share gains in student retention and five-year graduation rates as evidence of effectiveness.
\end{abstract}

Keywords: Retention; high impact practices; learning community; Latinx students; student success; tiered curriculum; student development.

\section{Introduction}

This report examines a three-tiered learning community model designed by a Latinx Studies Program (the Center) at a researchintensive university in the United States. The Center was founded with the mission of increasing college access for low-income and first generation Latinx students. Generally, learning communities (LCs) are characterized by common features that bring students together through linked courses and/or through frequent interaction, both socially and intellectually (Kuh, 2008). The Latinx LC at the Center fits this description because students first connect through their linked summer enrichment courses and then continue to take classes together through their first year while receiving structured wrap-around social and intellectual support that takes them all the way to college graduation.

Except where otherwise noted, content in this journal is licensed under a Creative Commons Attribution 4.0 International Licence. As an open access journal, articles are free to use with proper attribution. ISSN: 2205-0795 
According to the Association of American Colleges and Universities (AAC\&U, 2022), learning communities represent one of 11 high-impact practices (HIPs). Research has shown HIPs to be highly effective at improving student success as measured by student engagement and retention, particularly among under-represented communities (Kuh, 2008).

This report seeks to share how one learning community successfully implemented 10 of the 11 HIPs across the three tiers of their learning community. The learning community was developmentally structured to be an integrative space that engages students beyond coursework with both peers and instructors. Linked courses explore culturally relevant topics such as race, ethnic identity and belonging, as well as how academic content can be interdisciplinary (Kuh, 2008). The authors do not intend to imply that all 10 HIPs are necessary for success but rather seek to share a model of implementation that brought them success with this particular population.

\section{Description of the LC Model Used at the Center}

Inspired by Taylor and Haynes (2008) the Center utilized a three-tier learning community model, where each tier progressively builds on the other. The model includes three distinct phases: 1) The Pre-College Summer Enrichment Program (SEP); 2) a first-and second-year College Scholars Program (CoSch), and 3) the College-to-Career (C2C) Program, an undergraduate research and professional development experience designed for third-and fourth-year students. The Latinx LC began in 2007. This report covers the cohort years of 2007-2012.

In terms of marketing, when accepted to the university, students of all backgrounds receive information about a wide variety of university LCs, and they are invited to attend information sessions on LCs of interest. Additionally, self-identified Latinx students receive bilingual English/Spanish marketing materials about the Center's Latinx LC. Specifically, they receive an invitation to attend a bilingual information session so that families who do not speak English can obtain information and get their questions answered in a language they understand. Students from all disciplines and backgrounds may participate in the Latinx LC.

According to the Office of Institutional Research and Analysis at this university, retention and graduation for the full-time, first-time degree seeking, fall university cohort, for years 2007-2012, there were 14,699 total students of all races. Out of these students, approximately 118 total students (.8\%) elected to begin their university journey at the Center, as part of the SEP. The Latinx LC typically serves 150 to 200 students per year who are spread across the three phases of the program. For the years reported, an average of $88 \%$ of SEP students self-identified as Latinx.

It is important to note, that students may elect to join the Latinx LC in either the summer prior to the start of fall classes with SEP, or they may elect to join with the CoSch, in their first fall semester, after graduating from high school. The data cited only covers those students who enrolled in the summer with SEP and received the full complement of 10 HIPs.

There are four full-time bilingual English/Spanish staff members (a Director, Assistant Director and two advisors), three tenured faculty and several instructors. The Center is endowed and offers a range of scholarships and funding for participants, including undocumented students. A comprehensive description of each LC tier and the corresponding HIPs can be found below.

\section{Tier One: Summer Enrichment Pre-College Program (SEP)}

The SEP is a 6-week, non-credit, non-residential, free, pre-college summer bridge program that occurs two full days a week, allowing low-income students to work summer jobs and save money for classes. As a way to off-set potential wage losses, students also receive stipends for successful completion of summer coursework.

The SEP kicks off a cohort group's first-year experience. According to Strayhorn (2012) developing social support is just as critical as developing academic support. As a result, it is the program's formative phase, where rising freshman (first-year) students meet each other and develop a sense of belonging. The design is relational with collaborative assignments and familylike mealtimes, where faculty, staff and students eat together. Team-building activities, such as a campus scavenger hunt and excursions to cultural events and museums, strengthen student social support networks. Many activities are led by trained upper-level college students who are peer mentors and liaisons to the college experience. The SEP incorporates the following three HIPs: 


\section{Common Intellectual Experiences}

The SEP provides a Pre-English and Pre-math intervention, an introduction to Latinx Studies, peer mentoring and tutoring services. SEP students are cohorted and move through their summer, first- and second-year experience together. Assignments, which are interdisciplinary and foster collaboration across courses and include discussion-based readings and a common essay final exam, are graded collectively. This provides what Tinto and Pusser (2006, p. 16) called "pedagogies of engagement" that strengthen student-to-student and student-faculty relationships. These "required common courses" as Kuh (2008, p. 2) describes, are organized under the theme of Latinx Studies allowing students to earn an optional minor to complement their chosen field.

\section{Writing Intensive Courses}

The SEP Pre-English, Pre-math and Pre-Latinx Studies are writing intensive courses taught by faculty. The Pre-English class was originally designed for English learners, to build college writing competence and confidence. It now offers writing across the curriculum, suggested by Condon \& Rutz (2012) and Kuh (2008), where students practice various forms of writing, including creative and expository, for different audiences. In Pre-math, students research significant historical figures and discoveries in math and science as well as the application of mathematical concepts in students' daily lives. Pre-English and math provide differentiated instruction across levels designed to prepare students for rigorous first-year gateway English and math courses. In Pre-Latinx Studies, the cohort explores the relationship between history and cultural identity through personal narratives supported by inquiry-based research practices that build intercultural knowledge for the diversity/global learning requirements they will take during their first and second year.

\section{Peer Mentoring}

Critical to the LC experience is peer mentoring (Baier, Gonzales, Sawilowsky, 2019). The cohort students are assigned upperdivision peer mentors who shadow them from SEP into their first two years of college, providing academic, social, and emotional support. Tinto and Pusser (2006, p. 7) suggest that such support is critical for under-represented students and should be "connected to, not isolated from the learning environment." Peer mentors provide continuity as they are also cohort alumni who have completed SEP, CoSch and/or C2C courses, and thus are well-positioned to support throughout the first-year experience. Peer mentors are paid and undergo a three-day comprehensive training activity each summer and each fall (six days in total) by the program and the university. Peer mentors also attend bi-monthly meetings and are supervised by the Center's Associate Director. Survey data for the years indicated, 84\% (103/122) of LC respondents felt their peer mentor helped them to feel more welcomed on campus and $66 \%$ (81/122) felt their transition was easier due to their peer mentor.

\section{Tier Two: The College Scholars Component (CoSch)}

The first and second year CoSch component builds on the SEP and has three primary goals: 1) to provide a family-friendly environment with access to bilingual staff, faculty and advisors; 2) to match first- and second-year students with upper-division peer mentors (the same peer mentors they had over the summer) who can provide socio-emotional support and help students through required gateway college English and math courses; and, 3) to provide a culturally and linguistically responsive curriculum which aids belonging and success. Similar to the SEP, the CoSch provides students with Common Intellectual Experiences designed to strengthen the outcomes gained during the summer while building on the following three HIPs.

\section{Common Intellectual Experiences}

CoSch student cohorts enter their first year with a common course schedule. Together, they take gateway courses such as college English and math with an instructor sensitive to the needs of first-generation college students. These courses were often obstacles to graduation. They were thus, front-loaded to the fall semester immediately following SEP when content was still fresh in their memory. LC pass rates for math were $78 \%$ for the first year studied, while only $44 \%$ of non-LC university students passed this same class. In the subsequent year, university pass rates were 59\% compared to $100 \%$ for LC students (Gonzales et al., 2015). For the years studied, the average LC pass rate was $73 \%$ overall for college math. Similarly, for College English, $90 \%$ pass rate for year one and $70 \%$ year two, with $76 \%$ being the average pass rate for LC students for the years under study. LC students also take Latinx Studies and a First-Year Seminar together. This cohort process through linked courses inspires deeper relationships and provides common intellectual experiences as supported by Kuh (2008), and reinforces connections with both peer and academic support networks established during the SEP. 


\section{First-Year Seminar and Experiences}

The CoSch First-Year Seminar is a three credit hour course that empowers student cohorts with the academic and social skills necessary for success at a research institution (Kuh, 2008), including note-taking, engaged reading, and time management. The course also teaches students about non-academic issues which can affect student success, such as financial aid and financial literacy and how to access campus resources such as counseling and student life, as well as timely advising, proper course sequencing and registration (Thomas et al., 2018). The first-year experience also engages students in ways that build community and belonging, which, according to Strayhorn (2012), is critical to first-generation student success. Surveys about the "most useful aspects of the program," demonstrated this to be significant as $17 \%$ of respondents mentioned words like "friendship" and/or "community", while $48 \%$ specifically referenced connections to and/or support from a teacher, a staff member, a peer advisor or general "helpfulness" when referencing the LC.

\section{Diversity/Global Learning}

Diversity/global learning courses expose students to diverse cultures, life experiences and worldviews (Kuh, 2008). First year CoSch participants enroll in the Introduction to Latinx Studies course. Second-year students take the History of Colonial Latin America, which fulfills the university's Historical Studies (HS) requirement. Students also choose from offerings such as Chicanx Literature and Culture or Puerto Rican Literature and Culture which fulfill the university's Global Culture requirement. The Latinx Studies emphasis leads to a minor and develops intercultural sensitivity or the ability to understand, relate to and respect complex cultural differences (Hammer et al., 2003).

\section{Tier Three: College to Career Component (C2C)}

The $\mathrm{C} 2 \mathrm{C}$ prepares juniors and seniors to transition from college to career and/or graduate studies. C2C students also serve as peer mentors for SEP and CoSch students while benefiting from peer mentoring themselves. The SEP and CoSch Peer mentors focus on building academic skills, while graduate students mentor $\mathrm{C} 2 \mathrm{C}$ mentees on resume writing, identifying suitable internship opportunities and/or preparation for graduate school entrance exams such as the LSAT and MCAT and access to graduate school prep-programs such as McNair Scholars and the King-Chávez-Parks Fellowship Initiative. The C2C incorporates the four following HIPs:

\section{Capstone Courses and Projects}

The third-year capstone course "Learning About Your Community Through Research" is a culminating experience that requires students to create an original research project integrating what they've learned as proposed by Kuh (2008). During class, students develop research questions, craft their proposals, then spend an additional six hours per week collecting data in the field. One year, all students collected data at a local elementary school and then presented their findings at the annual Latinx Undergraduate Research conference described in the next section.

\section{Undergraduate Research}

Undergraduate research should "involve students with actively contested questions, empirical observation, cutting-edge technologies, and the sense of excitement from finding answers to important questions” (Kuh, 2008, p. 2). The program's annual Latinx Undergraduate Research course and subsequent conference meet these goals. The conference, designed as a showcase for students in the capstone course, originally featured about twelve poster-board research presentations. Over a decade later the conference has grown to include over 200 poster-board, panel and plenary presentations, by undergraduate and graduate students, as well as faculty representing more than 20 universities from 10 different states. The conference has been a "game-changer" increasing student interest in graduate school, especially for STEM careers, a finding consistent with Kuh (2008) and Eagan and colleagues (2013).

\section{Service-Learning, Community-Based Learning}

According to Kuh (2008), community-based learning is linked to a course allowing students to apply content knowledge in the field, analyze and solve community problems, and then return to the classroom for debrief and reflection as exemplified through the capstone course described above. Modeling good citizenship, working with community partners and giving back is another goal described by Kuh (2008) and exemplified by the C2C. Each year, the program develops a series of projects for Cesar 
Chávez Day ${ }^{1}$ and Latinx Heritage Month. ${ }^{2}$ Projects include neighborhood beautification activities, outreach for local charities, fundraising for various causes, film screenings and guest lectures.

\section{Internships}

The C2C connects students with professional mentors in their chosen fields who introduce career opportunities, help with networking and facilitate job shadowing experiences. Professional mentors meet with student mentees a minimum of once a month over a nine-month period and attend to professional dress, communication and etiquette. They help students find corporate grants and scholarships, summer job placements, co-op opportunities and internships with local businesses and national corporations. Opportunities are often paid and include professional coaching. Of all students enrolled in C2C, 100\% were placed in career internships of relevance to their major. Many leveraged their internships to gain full-time employment upon graduation.

\section{Conclusion}

By sharing the implementation of HIPs at their institution, the authors hope others can investigate, replicate or expand the success experienced by this one Latinx studies program. Publications in progress will report increased four-and six-year graduation rates. A previous publication reported statistically significant learning outcomes and improvement in first-to-secondyear retention, from a pre-LC low of $48.3 \%$ in 2004 to a post-LC high of $86.8 \%$ in 2010 (Gonzales et al., 2015). In fact, the LC began to outpace university FTIACs (First-Time-in-Any-College students) in 2008, with an $85.3 \%$ retention rate versus $77.1 \%$ for their non-LC FTIAC peers (Gonzales et al., 2015). These increases occurred without any increase in institutional selectivity (admission criteria) as measured by high school grade point average and standardized test scores. Furthermore, similar improvements in five-year graduation rates, rising from a pre-LC low of $2.5 \%$ in 2006 to a post-LC high of $22.6 \%$ with the 2009 cohort, almost eliminated any attainment gap between LC participants and their non-LC FTIAC peers. This is important given that LC students were statistically among the least well prepared at the university (Gonzales et al., 2015).

This practice report describes how one program embedded HIPs within an LC model for Latinx student success. Pedagogical practices were designed to benefit students of diverse backgrounds including historically underserved students with unequal access to college prep resources and high-impact learning experiences. Though academic institutions strive to implement as many HIPs as possible (Axelson \& Flick, 2010; Kuh, 2008), few have reported singular models of success that integrate almost all HIPs (Kilgo et al., 2015). Other post-secondary institutions may adapt and modify any of the program components and implementation of HIPS for their own needs and communities. Recently, the AAC\&U added an eleventh HIP, e-portfolios, as a teaching, learning and assessment tool (Watson et al., 2016). Given the pandemic shift to online learning, this would be an important future direction for expanding LC initiatives.

\footnotetext{
${ }^{1}$ César Chávez Day is a day of service and learning which commemorates the life and work of César Chávez, a Mexican American labor and civil rights activist, who co-founded the United Farm Workers (UFW) union. César Chávez Day became a U.S. federal commemorative holiday in 2014 and is celebrated on March 31 of each year.

${ }^{2}$ The Latinx Heritage Month, also known as Hispanic Heritage Month, is celebrated in the United States between September 15 and October 15. This month-long celebration recognizes the histories, cultures, contributions, and achievements of Americans whose ancestry is derived from regions in Latin America and the Spanish peninsula.
} 


\section{References}

American Association of Colleges and Universities (2022). High Impact Practices. https://www.aacu.org/trendingtopics/high-impact

Axelson, R. D., \& Flick, A. (2010). Defining student engagement. Change: The Magazine of Higher Learning, 43(1), 38-43. https://doi.org/10.1080/00091383.2011.533096

Baier, S. T., Gonzales, S. M., Sawilowsky, S. S. (2019). A successful combination of developmental courses and learning communities. Journal of Developmental Education, 42(3), 2-4, 6-8, 28.

Condon, W., \& Rutz, C. (2012). A taxonomy of writing across the curriculum programs: Evolving to serve broader agendas. College Composition and Communication, 64(2), 357-382.

Eagan Jr, M. K., Hurtado, S., Chang, M. J., Garcia, G. A., Herrera, F. A., \& Garibay, J. C. (2013). Making a difference in science education: The impact of undergraduate research programs. American Educational Research Journal, 50(4), 683713, https://dx.doi.org/10.3102\%2F0002831213482038

Gonzales, S. M., Brammer, E.C., Sawilowsky, S. (2015). Belonging in the academy: Building a "casa away from casa" for Latino/a undergraduate students. Journal of Hispanic Higher Education, 14(3), 223-239. https://doi.org/10.1177\%2F1538192714556892

Hammer, M. R., Bennett, M. J., \& Wiseman, R. (2003). Measuring intercultural sensitivity: The intercultural development inventory. International Journal of Intercultural Relations, 27(4), 421-443. https://psycnet.apa.org/doi/10.1016/S01471767(03)00032-4

Kilgo, C. A., Sheets, J. K. E., \& Pascarella, E. T. (2015). The link between high-impact practices and student learning: Some longitudinal evidence. Higher Education, 69(4), 509-525, https://doi.org/10.1007/s10734-014-9788-Z

Kuh, G. D. (2008). Excerpt from high-impact educational practices: What they are, who has access to them, and why they matter. Association of American Colleges and Universities, 14(3), 28-29.

Strayhorn, T. L. (2012). College students' sense of belonging: A key to educational success for all students. Routledge.

Taylor, K., \& Haynes, C. (2008). A framework for intentionally fostering student learning. About Campus, 13(5), 2-11. https://doi.org/10.1002/abc.265

Thomas, D. T., Walsh, E. T., Torr, B. M., Alvarez, A. S., \& Malagon, M. C. (2018). Incorporating high-impact practices for retention: A learning community model for transfer students. Journal of College Student Retention: Research, Theory \& Practice, 23(2), 243-263, https://doi.org/10.1177\%2F1521025118813618

Tinto, V., \& Pusser, B. (2006). Moving from theory to action: Building a model of institutional action for student success. National Postsecondary Education Cooperative, National Postsecondary Education Cooperative

Watson, C. E., Kuh, G. D., Rhodes, T., Light, T. P., \& Chen, H. L. (2016). ePortfolios-The eleventh high impact practice. International Journal of ePortfolio, 6(2), 65-69.

\section{Please cite this article as:}

Gonzales, S.M., Baier, S.T., \& Brammer, E.C. (2022). Are you HIP?: How one Latinx learning community integrates ten high-impact practices to foster student success. A practice report. Student Success. 13(1), 74-79. https://doi.org/10.5204/ssj.1907

This practice report has been accepted for publication in Student Success. Please see the Editorial Policies under the 'About' section of the Journal website for further information.

Except where otherwise noted, content in this journal is licensed under a Creative Commons Attribution 4.0 International Licence. As an open access journal, articles are free to use with proper attribution. ISSN: 2205-0795 